\title{
Elektronische Abstracteinreichung Schritt für Schritt
}

1

Unter der Internet-Adresse http://abstracts.urban-vogel.de

finden Sie das Kongressverwaltungssystem des Verlages

- Urban \& Vogel, in dem das Allergo Journal erscheint. Wählen

\section{URBAN \& VOGEL}

Kongressverwaltungssystem des Verlages Urban \& Vogel

Aktuell kónnen Sie sich bei folgenden Veranstaltungen anmelden oder Abstracts eingeben:

- 28. Mainzer Allerole- Workshoos

Abstracteinreichung: Abstract-Einreichung bevorzugt in englischer Sprache bis 30. November 2015

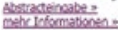

Sie aus der Veranstaltungsliste den 28. Mainzer Allergie-Workshop 2016 aus. Beim folgenden Login geben Sie bitte ein:

\section{Benutzer: Mainz}

Passwort: 2016

Sie gelangen dann direkt zur ersten Eingabemaske.
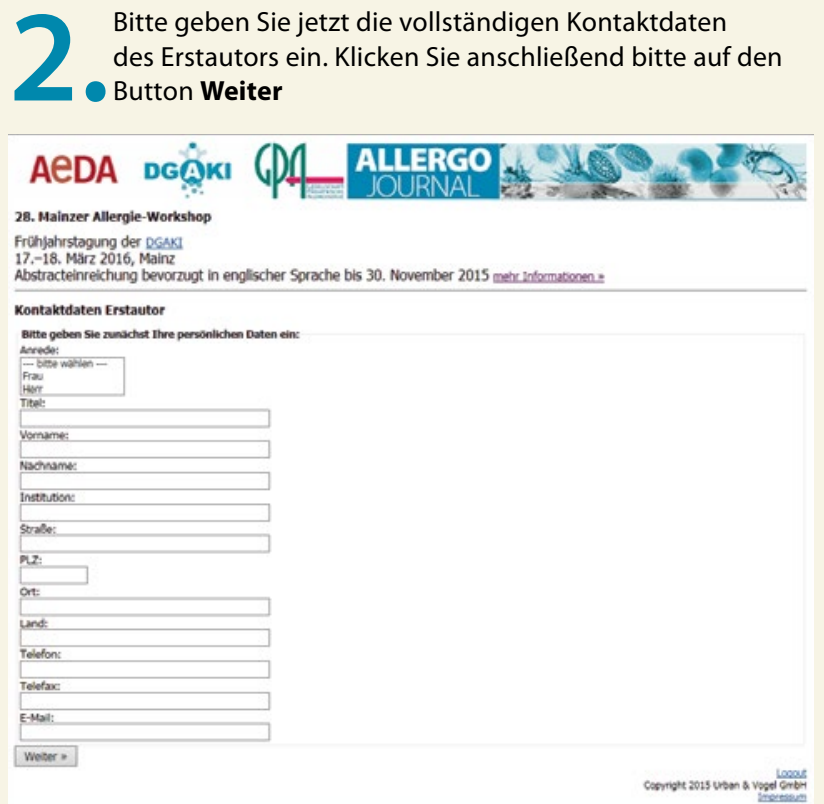

\section{Bitte geben Sie \\ jetzt zunächst alle \\ - Co-Autoren des}

Abstracts (maximal 15) mit

Titel, Vornamen, Nach-

namen, Institution und Ort an. Durch jedes Klicken auf den Text weiterer Autor erscheint ein zusätzliches Eingabefeld. Sobald Sie alle Co-Autoren vollständig eingegeben haben, klicken Sie wieder auf Weiter.
4.

Mit der jetzt folgenden Maske kann dann der eigentliche Abstracttext eingegeben werden. Bitte stimmen Sie zuvor

durch Ankreuzen des entsprechenden Kästchens der Publikation Ihrer Daten im Programmheft des Workshops, im Allergo Journal und auf der Homepage der DGAKI zu. Dies ist aus presse- und urheberrechtlichen Gründen erforderlich. Wählen Sie dann aus, ob Sie Ihre

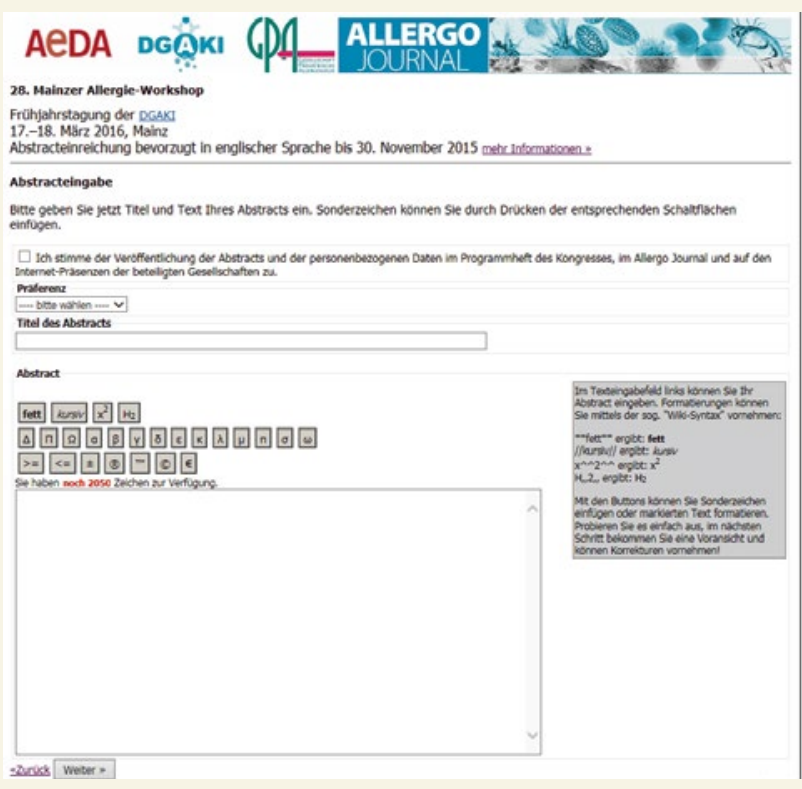

Daten bevorzugt als Vortrag oder als Poster präsentieren wollen. Danach können Sie direkt Titel und Text Ihres Beitrages - bevorzugt in englischer Sprache - eintippen oder auch aus der Zwischenablage hineinkopieren. Es stehen für den Text insgesamt maximal 2.000 Zeichen zur Verfügung, Sonderzeichen können über die entsprechenden Schaltflächen eingeben werden. Es ist weiter möglich, Text fett, kursiv sowie hoch- oder tiefgestellt darzustellen. Bitte klicken Sie nach Abschluss aller Eingaben wiederum auf Weiter.

Im letzten Schritt können Sie alle Eingaben nochmals kontrol-
lieren. Bitte beachten Sie, dass Ihr Abstract genau so gedruckt wird, wie

Sie es eingegeben haben. Falls Sie noch Fehler entdecken, gelangen Sie mit einem Klick auf Korrigieren wieder $\mathrm{zu}$ rück in den Überarbeitungsmodus. Wenn alles korrekt eingegeben ist, klicken Sie auf OK, Speichern. Wenn Sie das Bild rechts sehen, haben Sie Ihre

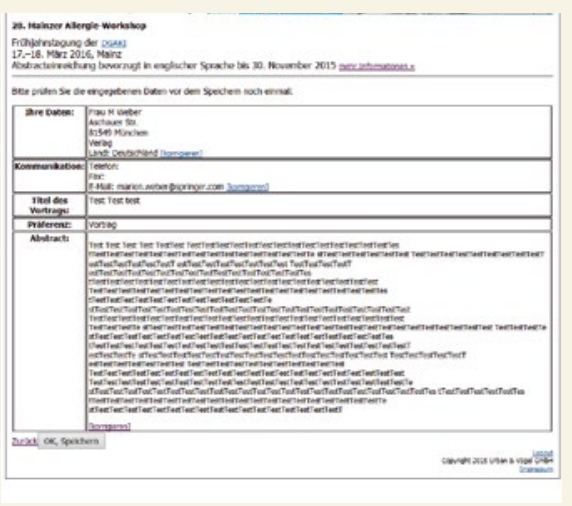
Daten erfolgreich

beim Mainzer Allergie-Workshop 2016 eingereicht. Die Seite können Sie als Beleg für Ihre Eingabe und Anmeldung ausdrucken. 